\title{
Models for Assessment and Computational Analysis of Hardness of the Heat Affected Zone in Water Cooled Aluminum Weldment
}

\author{
C. I. Nwoye ${ }^{1 *}$, C. N. Anyakwo ${ }^{2}$, E. Obidiegwu ${ }^{3}$ and N. E. Nwankwo ${ }^{1}$ \\ ${ }^{* 1}$ Department of Metallurgical Engineering and Materials Engineering Nnamdi Azikiwe \\ University, Awka, Nigeria. \\ ${ }^{2}$ Department of Materials and Metallurgical Engineering Federal University of Technology, \\ Owerri, Nigeria. \\ ${ }^{3}$ Department of Metallurgical and Materials Engineering University of Lagos, Nigeria. \\ *Corresponding Author: chikeyn@yahoo.com
}

\section{ABSTRACT}

Models have been derived for assessment and computational analysis of the hardness of the heat affected zone (HAZ) in aluminum weldment. The general model;

$$
\gamma=1.2714[(\alpha \beta / \alpha+\beta)]
$$

was found to predict the HAZ hardness of aluminum weldment cooled in water as a function of the HAZ hardness of both mild steel and cast iron welded and cooled under the same conditions. The maximum deviations of the model-predicted HAZ hardness values $\gamma, \alpha$ and $\beta$ from the corresponding experimental values $\gamma_{\exp }, \alpha_{\exp }$ and $\beta_{\exp }$ were less than $0.02 \%$ respectively.

Keywords: Model, Hardness, Heat Affected Zone, Aluminum Weldments, Mild Steel, Cast Iron.

\section{INTRODUCTION}

Heat-affected zone (HAZ) has been successfully investigated and reported [1] as basically the area of base material, either a metal or a thermoplastic, which has had its microstructure and properties altered by welding or heat intensive cutting operations. This change in the area surrounding the weld results from the corporate inputs of the heat from the welding process and subsequent re-cooling. The extent and magnitude of property change depends primarily on the base material, the weld filler metal, as well as the amount and concentration of heat input by the welding process used. 
It has been shown [1] that the thermal diffusivity of the base material plays very significant role. High diffusivity results in high cooling rate of the material and this translates into relatively small HAZ. Alternatively, a low diffusivity leads to slower cooling and a larger HAZ. The amount of heat inputted by the welding process plays an important role as well, as processes like oxyfuel welding use high heat input and increase the size of the HAZ. Processes like laser beam welding and electron beam welding give a highly concentrated, limited amount of heat, resulting in a small HAZ. Arc welding falls between these two extremes, with the individual processes varying somewhat in heat input.

Recent report [2] has confirmed that weldment cracking results to low mechanical properties such as hardness and impact strength in welded parts, the heat affected zone being located adjacent to the immediate welded area or fusion. Studies [3] on HAZ have shown that the most important mechanical property associated with it is the hardness since it gives an indication of the degree of embrittlement there. Lancaster [3] found that the heat affected zone hardness produced by any given welding operation depends on the cooling rate experienced by the HAZ. Application of enhanced rapid rate of cooling favours the formation of hard and brittle martensite in all the sub zones of the HAZ or increases the martensite region in size relative to the other regions. The presence of martensite in the HAZ results in a very high hardness value for the heat affected zone. Slow cooling favours a better microstructure needed for engineering applications.

Nwoye [4] found that the hardness of HAZ in aluminum, cast iron and mild steel weldments cooled in kerosene is the same as the hardness value of the same materials cooled in groundnut oil [4]. This implies that

$$
\mathrm{H}_{\mathrm{G}}=\mathrm{H}_{\mathrm{K}}
$$

Where

$$
\begin{aligned}
& \mathrm{H}_{\mathrm{G}}=\text { Hardness of HAZ cooled in groundnut oil } \\
& \mathrm{H}_{\mathrm{K}}=\text { Hardness of HAZ cooled kerosene }
\end{aligned}
$$

Nwoye [4] reported that $8-10 \%$ less hardness than that from water occurs when kerosene or groundnut oil is used as quenchant for HAZ. The researcher discovered that quenching the HAZ with kerosene or groundnut oil gives approximately $8-10.7 \%$ more hardness than that from quenching with air. The researcher found that palm oil gave the lowest hardness and cooling rate on the HAZ.

Nwoye et al. [5] derived a model for the predictive analysis of hardness of the heat affected zone in aluminum weldment cooled in groundnut oil. The general model;

$$
\beta=0.5997 \sqrt{ }(\gamma \alpha)
$$

was found to be dependent on the hardness of the heat affected zone (HAZ) in mild steel and cast iron weldments cooled in same media. Re-arrangement of these models could be done to evaluate the HAZ hardness of mild steel or cast iron respectively as in the case of aluminum. 


$$
\begin{aligned}
& \alpha=\left(\frac{\beta^{2}}{0.3596 \gamma}\right) \\
& \gamma=\left(\frac{\beta^{2}}{0.3596 \alpha}\right)
\end{aligned}
$$

The respective deviations of the model-predicted HAZ hardness values $\beta, \gamma$ and $\alpha$ from the corresponding experimental values was less $0.02 \%$.

Quadratic and linear models [6] have been derived for predicting the heat-affected zone (HAZ) hardness of water cooled cast iron weldment in relation to the combined and respective values of the heat-affected zone hardness of aluminum and mild steel welded and cooled under the same conditions. The quadratic model is expressed as:

$$
\theta=\left(\frac{3.0749 \beta-\gamma}{2}\right)+\sqrt{ }\left(\left[\frac{\gamma-3.0749 \beta}{2}\right)^{2}-\gamma \beta\right)
$$

It was found that the validity of the quadratic model is rooted on the fractional expression; $\gamma / 3.0749 \theta+\gamma / 3.0749 \beta+\theta / 3.0749 \beta=1$. The respective deviations of the model-predicted heat-affected zone hardness values of aluminum, cast iron and mild steel from the corresponding experimental values were less than $0.01 \%$ which is quite insignificant, indicating reliability of the model. The linear models expressed as: $\theta=2.2051 \gamma$ and $\theta=$ $1.8035 \beta$, on the other hand predict the HAZ hardness of cast iron weldment cooled in water given the values of the HAZ hardness of aluminum or/and mild steel welded and cooled under the same conditions are known.

Successful attempt [7] has been made to derive quadratic and linear models for predicting the HAZ hardness of air cooled cast iron weldment in relation to the combined and respective values of HAZ hardness of aluminum and mild steel welded and cooled under the same conditions. It was discovered that the general model;

$$
\theta=[2.9774 \beta-\gamma] / 2+\sqrt{ }\left[((\gamma-2.9774 \beta) / 2)^{2}-\gamma \beta\right]
$$

predicts the HAZ hardness of cast iron weldment cooled in air as a function of the HAZ hardness of both aluminum and mild steel welded and cooled under the same conditions. The linear models; $\theta=2.2391 \gamma$ and $\theta=1.7495 \beta$ on the other hand predict the HAZ hardness of cast iron weldment cooled in air as a function of the HAZ hardness of aluminum or mild steel welded and cooled under the same conditions. It was found that the validity of the model is rooted on the fractional expression; $\gamma / 2.9774 \theta+\gamma / 2.9774 \beta+\theta / 2.9774 \beta=1$ since the actual computational analysis of the expression was also equal to 1, apart from the fact that the expression comprised the three metallic materials. The respective deviations of the model- 
predicted HAZ hardness values $\theta, \gamma$, and $\beta$ from the corresponding experimental values $\theta_{\text {exp, }}$ $\gamma_{\exp }$ and $\beta_{\exp }$ was less than $0.003 \%$.

Models have been derived [8] for the evaluation of the HAZ hardness of cast iron weldment cooled in groundnut oil in relation to the respective and combined values of HAZ hardness of aluminum and mild steel welded and cooled under the same conditions. The linear models; $\alpha$ $=2.2330 \gamma, \alpha=1.7934 \beta$ and $\beta=1.2451 \gamma$, were found to predict the HAZ hardness of cast iron weldment cooled in groundnut oil as a function of the HAZ hardness of aluminum or mild steel welded and cooled under the same conditions. It was also discovered that the general model;

$$
\alpha=1.7391 \gamma+0.3967 \beta
$$

can predict the HAZ hardness of cast iron weldment cooled in groundnut oil as a function of the HAZ hardness of both aluminum and mild steel welded and cooled under the same conditions. The respective deviations of the model-predicted HAZ hardness values $\gamma, \beta$ and $\alpha$ from the corresponding experimental values $\gamma_{\exp }, \beta_{\text {exp }}$, and $\alpha_{\text {exp }}$, was less $0.8 \%$ indicating the reliability and validity of the model.

The present study aims at deriving models for assessment and computational analysis of the hardness of the heat affected zone (HAZ) in water cooled aluminum weldment, as a function of the respective and combined values of HAZ hardness of mild steel and cast iron welded and cooled under the same conditions.

\section{MATERIALS AND METHODS}

Aluminum, mild steel and cast iron were cut and welded using the shielded metal arc welding technique and the hardness of the HAZ (cooled in water maintained at room temperature) tested. The hardness of the HAZ is as presented in Table 2. The full details of the experimental procedures and equipment used are presented in the previous report [4]. Table 1 shows the welding current and voltage used.

Table 1: Variation of materials with welding current and voltage [4].

\begin{tabular}{|l|l|c|c|}
\hline Materials & Current Type & $\begin{array}{l}\text { Welding } \\
\text { Current }\end{array}$ & $\begin{array}{l}\text { Welding } \\
\text { (V) }\end{array}$ \\
\hline Aluminum & Direct (d.c) & 120 & 280 \\
Cast Iron & $\begin{array}{l}\text { Alternating } \\
\text { (a.c) }\end{array}$ & 180 & 220 \\
Mild Steel & $\begin{array}{l}\text { Alternating } \\
\text { (a.c) }\end{array}$ & 180 & 220 \\
\hline
\end{tabular}


Table 2: Hardness of HAZ in weldments [4]

\begin{tabular}{|l|l|}
\hline Materials & $\begin{array}{l}\text { HAZ } \\
(\mathrm{VHN})\end{array}$ \\
\hline Aluminum & 458 \\
Cast Iron & 1010 \\
Mild Steel & 560 \\
\hline
\end{tabular}

\section{MODEL FORMULATION}

Results of experiment [4] carried out at Metallurgical and Materials Engineering Department of Federal University of Technology, Owerri were used for this work. Computational analysis of the experimental results [4] shown in Table 2 resulted in Table 3.

Table 3: HAZ Hardness ratio between aluminum, mild steel, and cast iron weldments cooled in water.

\begin{tabular}{|c|c|c|}
\hline $\begin{array}{l}\text { Ratio of } \\
\text { symbols } \\
\text { designating } \\
\text { HAZ hardness }\end{array}$ & $\begin{array}{l}\text { Ratio of HAZ } \\
\text { hardness } \\
\text { values }\end{array}$ & $\begin{array}{l}\text { Results of the } \\
\text { Ratio of HAZ } \\
\text { hardness values }\end{array}$ \\
\hline$\gamma / \alpha$ & $458 / 1010$ & 0.4535 \\
$\gamma / \beta$ & $458 / 560$ & 0.8179 \\
$\alpha / \beta$ & $1010 / 560$ & 1.8036 \\
\hline
\end{tabular}

Table 3 shows that the hardness of HAZ in aluminum weldment cooled in water is a function of the hardness of HAZ in cast iron and mild steel weldment also cooled in water. Therefore,

$$
\begin{aligned}
& \gamma=0.4535 \alpha \\
& \gamma=0.8179 \beta \\
& \alpha=1.8036 \beta
\end{aligned}
$$

Adding eqns. (8) and (9) as arranged in Table 2;

$$
\begin{gathered}
\frac{\gamma}{\alpha}+\frac{\gamma}{\beta} \\
\frac{\gamma \beta+\gamma \alpha}{\alpha \beta}=1.2714 \\
\gamma \beta+\gamma \alpha=1.2714 \alpha \beta \\
\gamma(\beta+\alpha)=1.2714 \alpha \beta \\
\gamma=1.2714\left(\begin{array}{c}
\alpha \beta \\
\alpha+\beta
\end{array}\right)
\end{gathered}
$$

The derived model (general model) is equation (15) 
Where

$\gamma=$ Model-predicted hardness of HAZ in aluminum weldment cooled in water (VPN)

$\beta=$ Model-predicted hardness of HAZ in mild steel weldment cooled in water (VPN)

$\alpha=$ Model-predicted hardness of HAZ in cast iron weldment cooled in water (VPN)

\section{BOUNDARY AND INITIAL CONDITIONS}

The welding process was carried out under atmospheric condition. After welding, weldments were also maintained under atmospheric condition. Welding current and voltage used are $180 \mathrm{~A}$ and $220 \mathrm{~V}$ respectively. $\mathrm{SiO}_{2}$-coated electrodes were used to avoid oxidation of weld spots. The coolants used were maintained at $25^{\circ} \mathrm{C}$ (room temperature). Volume of coolants used; $1000 \mathrm{~cm}^{3}$. No pressure was applied to the HAZ during or after the welding process. No force due to compression or tension was applied in any way to the HAZ during or after the welding process. The sides and shapes of the samples are symmetries.

\section{MODEL VALIDATION}

The derived model was validated by evaluating the model-predicted values of HAZ hardness in aluminum weldment cooled in water $\gamma$ and comparing them with the corresponding values obtained from the experiment $\gamma_{\exp }$ [4]. Following re-arrangement of the model equation; (15), the values of $\alpha$ and $\beta$ were also evaluated as;

$$
\begin{aligned}
& \alpha=\left(\frac{1.2714}{\gamma}-\frac{1}{\beta}\right)^{-1} \\
& \beta=\left(\frac{1.2714}{\gamma}-\frac{1}{\alpha}\right)^{-1}
\end{aligned}
$$

and compared with their respective corresponding experimental values $\alpha_{\exp }$ and $\beta_{\exp }$ to further establish the validity of the model. The model-predicted values of $\gamma, \alpha$ and $\beta$ are shown in Table 3.

Analysis and comparison between the model-predicted values $\gamma, \alpha, \beta$ and the respective corresponding experimental values $\gamma_{\text {exp }}, \alpha_{\exp }$ and $\beta_{\text {exp }}$ reveal deviations of model data from the experimental data. This is attributed to the non-consideration of the chemical properties of the coolant and the physiochemical interactions between the materials (aluminum, mild steel and cast iron) and the coolant which is believed to have played vital roles in modifying the microstructure of the HAZ during the coolant process. These deviations necessitated the introduction of correction factor to bring the model-predicted values to exactly that of the corresponding experimental values.

Deviation (Dv) of the model-predicted HAZ hardness values $(\gamma, \alpha$ and $\beta$ ) from the corresponding experimental values $\gamma_{\exp }, \alpha_{\exp }$ and $\beta_{\exp }$ is given by 


$$
\mathrm{Dv}=\left(\frac{\mathrm{M}_{\mathrm{H}}-\mathrm{E}_{\mathrm{H}}}{\mathrm{E}_{\mathrm{H}}}\right) \times 100
$$

Correction factor $(\mathrm{Cf})$ is the negative of the deviation i.e.

$$
\mathrm{Cf}=-\mathrm{Dv}
$$

Where

Dv $=$ Deviation of the model-predicted HAZ hardness values from the corresponding experimental values

$\mathrm{Cf}=$ Correction factor

$\mathrm{M}_{\mathrm{H}}=$ Model-predicted HAZ hardness values

$\mathrm{E}_{\mathrm{H}}=\mathrm{HAZ}$ hardness values from the experiment [4]

Therefore

$$
C f=-100\left(\frac{M_{H}-E_{H}}{E_{H}}\right)
$$

Introduction of the value of $\mathrm{Cf}$ from equation (20) into the models give exactly the corresponding experimental values $\gamma_{\exp }, \alpha_{\exp }$ and $\beta_{\exp }$ [4].

\section{RESULTS AND DISCUSSION}

A comparison of the HAZ hardness values from experiment and those of the model show model values very much within the range of the experimental values. Results of this comparison are presented in Tables 4 and 5. Model values of $\gamma$ evaluated from equations (8) and (9) and tabulated in Table 4 show that all the equations are valid since all of them gave almost the same corresponding experimental values $\gamma_{\text {exp. }}$.

Table 4: Comparison of the hardness of HAZ in aluminum, mild steel and cast iron weldments cooled in water as obtained from experiment [4] and as predicted by derived model (each material as a function of 1- material).

\begin{tabular}{|c|c|c|c|c|c|}
\hline $\mathrm{N}$ & Models derived & $\mathrm{M}_{\mathrm{H}}$ & $\mathrm{E}_{\mathrm{H}}$ & $\mathrm{Dv}(\%)$ & $\mathrm{Cf}(\%)$ \\
\hline 1 & $\gamma=0.4535 \alpha$ & 458.0350 & 458.00 & +0.0076 & -0.0076 \\
1 & $\gamma=0.8179 \beta$ & 458.0240 & 458.00 & +0.0052 & -0.0052 \\
1 & $\alpha=1.8036 \beta$ & 1010.0160 & 1010.00 & +0.0016 & -0.0016 \\
\hline
\end{tabular}

The value of $\alpha$ in equation (10) was evaluated to establish the validity of the model. It was found that the model-predicted $\alpha$ value was also almost the same as the corresponding

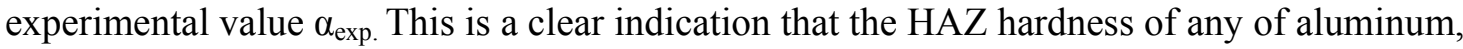
mild steel and cast iron weldments cooled in water can be predicted as a function of the HAZ hardness of any of the other two materials, providing each pair was cooled in water. Table 5 also indicates that the model-predicted value of $\alpha$ is approximately the same as the corresponding experimental value. 
Table 5: Comparison of the hardness of HAZ in aluminum, mild steel and cast iron weldments cooled in water as obtained from experiment [4] and as predicted by derived model (each material as a function of 2-materials).

\begin{tabular}{|c|c|c|c|c|c|}
\hline $\mathrm{N}$ & Models derived & $\mathrm{M}_{\mathrm{H}}$ & $\mathrm{E}_{\mathrm{H}}$ & $\mathrm{Dv}(\%)$ & $\mathrm{Cf}(\%)$ \\
\hline 2 & $\gamma=1.2714[(\alpha \beta / \alpha+\beta)]$ & 458.028 & 458.00 & +0.0061 & -0.0061 \\
2 & $\alpha=[(1.2714 / \gamma-1 / \beta)]^{-1}$ & 559.910 & 560.00 & -0.0161 & +0.0161 \\
2 & $\beta=[(1.2714 / \gamma-1 / \alpha)]^{-1}$ & 1010.101 & 1010.00 & +0.0100 & -0.0100 \\
\hline
\end{tabular}

$\mathrm{N}=$ No. of materials constituting the corresponding model as independent variable

It can also be seen from Table 5 that the model-predicted values of $\alpha$ and $\beta$ are also almost the same as the corresponding experimental values of $\alpha_{\exp }$ and $\beta_{\exp }$ respectively. Tables 4 and 5 indicate that the respective deviations of the model-predicted HAZ hardness values $\gamma, \alpha$ and $\beta$ from those of the corresponding experimental values $\gamma_{\exp }, \alpha_{\exp }$ and $\beta_{\exp }$ are all less than $0.02 \%$ which is quite negligible and within the acceptable model deviation range from experimental results. Furthermore, the values of $\alpha$ and $\beta$ (from equations (16) and (17) respectively) evaluated to be approximately equal to the respective corresponding experimental values $\alpha_{\text {exp }}$ and $\beta_{\exp }$ confirm the validity of the model. This also implies that the general model; equation (15) can predict the HAZ hardness of any of aluminum, mild steel and cast iron weldments cooled in water as a function of the HAZ hardness of the other two materials, providing the three materials constituting the model (aluminum, mild steel and cast iron) were cooled in water. Equation (15) is regarded as the general model equation because it comprises of the HAZ hardness of all the materials considered for the model formulation. Based on the foregoing, the models in equations (8), (9) and (10) are valid and very useful for predicting HAZ hardness of aluminum, mild steel and cast iron weldments cooled in water depending on the material of interest and the given HAZ hardness values for the other materials.

\section{CONCLUSION}

The derived models; $\gamma=0.4535 \alpha, \gamma=0.8179 \beta$, and $\alpha=1.8036 \beta$, can predict the HAZ hardness of aluminum weldment cooled in water as a function of the HAZ hardness of mild steel or cast iron welded and cooled under the same conditions. Similarly, the general model; $\gamma=1.2714[(\alpha \beta / \alpha+\beta)]$ can predict the HAZ hardness of aluminum weldment cooled in water as a function of the HAZ hardness of both mild steel and cast iron welded and cooled under the same conditions. Furthermore, re-arrangement of these models could be done to evaluate the HAZ hardness of mild steel or cast iron respectively as in the case of aluminum. The respective deviations of the model-predicted HAZ hardness values $\gamma, \alpha$ and $\beta$ from the corresponding experimental values $\gamma_{\exp }, \alpha_{\exp }$ and $\beta_{\exp }$ was less $0.02 \%$ indicating the reliability and validity of the model. 


\section{ACKNOWLEDGEMENT}

The authors are grateful to the management of Federal University of Technology, Owerri for providing the equipment used for this work.

\section{REFERENCES}

[1] Weman, K. (2003) Welding Process Handbook. CRC Press LLC, New York.

[2] Nnuka, E. E., Ovat, F. A., and Oseni, M. I., (2008) Effect of Electrode Types on the Mechanical Properties and Structure of Welded Steel Joints. JMME, 3(1):7-13.

[3] Lancaster, J. F., (1987) Metallurgy of Welding: The Mechanical Properties of the Heat Affected Zone, $4^{\text {th }}$ Edition, Allen and University, London. p45.

[4] Nwoye, C. I. (2008) Comparative Studies of the Cooling Ability of Hydrocarbon Based Media and their Effects on the Hardness of the Heat Affected Zone (HAZ) in Weldments JMME 3(1):35-38.

[5] Nwoye, C. I., Odumodu, U., Nwoye, C. C., Obasi, G. C., and Onyemaobi, O. O. (2009) Model for Predictive Analysis of Hardness of the Heat Affected Zone in Aluminum Weldment Cooled in Groundnut Oil Relative to HAZ Hardness of Mild Steel and Cast Iron Weldments Cooled in Same Media. New York Science Journal, 2(6): 93-98.

[6] Nwoye, C. I. (2009) Quadratic Model for Predicting the Hardness of Heat Affected Zone in Water Cooled Cast Iron Weldment In Relation to Similarly Cooled Aluminum and Mild Steel Weldments. Journal of Mineral and Materials Characterization and Engineering, 8(10):765-773.

[7] Nwoye, C. I. (2009) Quadratic and Linear Models for Predicting the Hardness of Heat Affected Zone in Air Cooled Cast Iron Weldment in Relation to the HAZ Hardness of Aluminum and Mild Steel Weldments Cooled in Same Media. Researcher Journal, $1(4): 1-6$.

[8] Nwoye, C. I., and Mbuka, I. E. (2010) Models for Predicting HAZ Hardness in cast iron Weldment Cooled in Groundnut Oil in Relation to HAZ Hardness of Aluminum and Mild Steel Weldments Cooled in Same Media. Materials Research Innovation, 14(4):312-315 